\title{
A Base Nacional Comum Curricular e o berçário
}

\author{
Fabiana Cristina Frigieri de Vitta* \\ Girlene de Albuquerque Cruz** \\ Bárbara Solana Scarlassara ${ }^{* *}$
}

A educação infantil no Brasil tem uma história recente. Ainda que as creches tenham sido criadas desde a década de 1970, seu caráter assistencialista, de proteção e cuidado às crianças cujas mães trabalhavam, permaneceu institucionalizado até a promulgação da Lei de Diretrizes e Bases da Educação - LDB - (BRASIL, 1996a), alterada por diferentes leis complementares.

Essa lei marca uma importante proposta de mudança para essa fase da educação, posto que ela passa a fazer parte da chamada educação básica, composta por educação infantil, ensino fundamental e ensino médio. Dessa forma, a creche, parte da educação infantil, diz respeito oficialmente à faixa etária de zero a três anos.

Desde então, vários outros documentos foram publicados pelo Ministério da Educação (MEC) com o objetivo de regulamentar e auxiliar a organização da educação infantil - creche e préescola: Referenciais Educacionais Nacionais para a Educação Infantil - RCNEI (1998) em 3 volumes, dois Planos Nacionais de Educação (2001 e 2014), Parâmetros de Qualidade para a Educação Infantil (2006), Diretrizes Curriculares Nacionais para a Educação Básica - DCNEB (2013), Diretrizes Curriculares Nacionais para a Educação Infantil DCNEI (2010), que está contida no documento DCNEB e, mais recentemente, as Bases Nacional Comum Curricular - BNCC (2017).

$\mathrm{Na}$ análise dos documentos oficiais (anteriores à BNCC) nota-se claramente que a creche é menos contemplada. Os textos, preocupamse em conceituar os vários componentes presentes na educação da criança de zero a cinco anos, mas são pouco específicos para a criança menor. Rosemberg (2012) mostra uma preocupação especial com a educação da criança pequena e, inclusive destaca que a produção acadêmica e o setor educacional pouco se preocupa com a creche e com os bebês, deixando essa fase ainda na informalidade, mesmo que já integrada oficialmente à educação básica, fato que se reflete na formação exigida para trabalhar junto a esse público. Coutinho, em uma análise sobre as políticas para a educação da criança de 0 a 3 anos no contexto brasileiro, mostra a desigualdade existente nas propostas para essa fase da educação e defende a "oferta de vagas para todas as crianças que as famílias optarem pela frequência à creche e uma

\footnotetext{
*Endereço Eletrônico: fabianavitta@ gmail.com

***Endereço Eletrônico: leny.girl@ @otmail.com

**** Endereço Eletrônico: basolana.to@ gmail.com
}

educação baseada em critérios claros de qualidade" (COUTINHO, 2017, p. 27).

Vitta, Silva e Zaniolo (2016) analisaram esses documentos, com exceção da BNCC, com o objetivo de verificar como conceituam a creche, a educação especial e o atendimento a todas as crianças de zero a três anos e identificaram que a união entre cuidado e educação nas atividades realizadas nessa fase continua incipiente, desvinculados da realidade prática que conta com profissionais sem capacitação para a organização das atividades que, ainda estão ligados a uma ideia assistencialista.

A análise desses textos nos permitiu verificar que há grande dificuldade na implementação de uma proposta de qualidade para a Educação Infantil que contemple a educação para todos, uma vez que existe uma gama de fatores interferindo para a organização de uma prática embasada em aspectos consistentes (VITTA; SILVA; ZANIOLO, 2016, p.23).

Ainda que haja uma ampla e calorosa discussão acerca da legitimidade da BNCC, pela interferência do estado e revisões em crescente dissintonia com um processo de participação democrática dos grupos interessados, o documento foi promulgado. Nesse sentido, este ensaio tem por objetivo fazer uma análise crítica de seu texto, no que diz respeito à fase da Educação Infantil, mais especificamente à faixa etária de a um ano e seis meses $(1 \mathrm{a} 6 \mathrm{~m})$, conforme a BNCC trata.

$\mathrm{O}$ primeiro documento publicado com o objetivo de orientar as práticas nessa fase da educação foi o RCNEI, que segundo sua apresentação pelo então Ministro da Educação e do Desporto (MEC), Sr. Paulo Renato Souza,

[...] foi concebido de maneira a servir como um guia de reflexão de cunho educacional sobre objetivos, conteúdos e orientações didáticas para os profissionais que atuam diretamente com crianças de zero a seis anos, respeitando seus estilos pedagógicos e a diversidade cultural brasileira (BRASIL, 1998a, p.05).

A proposta do RCNEI responde a um 
estudo elaborado pelo MEC que resultou na publicação "Proposta pedagógica e currículo em educação infantil: um diagnóstico e a construção de uma metodologia de análise" (BRASIL, 1996b) que aponta as diversidades de propostas curriculares e práticas para essa fase educacional, revelando diferentes soluções para problemáticas específicas de cada região do Brasil, mas também mostrando desigualdades na garantia de qualidade na oferta dos serviços.

Assim, o Referencial "é uma proposta aberta, flexível e não obrigatória, que poderá subsidiar os sistemas educacionais, que assim o desejarem, na elaboração ou implementação de programas e currículos condizentes com suas realidades e singularidades" (BRASIL, 1998a, p. 14). O RCNEI publicado em 1998 oferecia, além das conceituações dos aspectos que compõem o educar a criança de zero a cinco anos, conteúdos e objetivos pelos quais essa fase da educação deveria responsabilizar-se.

Amorim e Dias fazem uma discussão depreendida do processo histórico dos documentos para auxiliar na organização da educação infantil e apontam que esse documento não respeitava $o$ debate e os avanços relacionados à essa fase da educação e sua organização no contexto educacional, representando "um desvio de rota". Para substituir o RCNEI foram organizadas as DCNEI (AMORIM; DIAS, 2012).

As DCNEI, articuladas às DCNEB,

reúnem princípios, fundamentos e procedimentos definidos pela Câmara de Educação Básica do Conselho Nacional de Educação, para orientar as políticas públicas e a elaboração, planejamento, execução e avaliação de propostas pedagógicas e curriculares de Educação Infantil (BRASIL, 2010, p. 11).

Ou seja, as DCNEI são de observação obrigatória, trazendo uma série de definições relacionadas à essa fase educacional - Educação Infantil, Criança, Currículo, Proposta Pedagógica, concentrando-se bastante nesta última, assim definida:

Proposta pedagógica ou projeto político pedagógico é o plano orientador das ações da instituição e define as metas que se pretende para a aprendizagem e o desenvolvimento das crianças que nela são educados e cuidados. É elaborado num processo coletivo, com a participação da direção, dos professores e da comunidade escolar (BRASIL, 2010, p.13).
Define uma série de princípios que devem ser observados na construção da proposta pedagógica, incluindo organização do tempo e espaço, diversidade, avaliação. Por fim, designa ao MEC elaborar orientações para sua implementação "em processo democrático e com consultoria técnica especializada" (p. 31), o que parece ter resultado na BNCC. As DCNEI não tratam especificamente de conteúdo e objetivos educacionais.

No contexto atual, a BNCC vem então complementar as DCNEI, aprofundando e desenvolvendo aspectos dispostos nesta. Vem com a proposta de normatizar quais são as aprendizagens essenciais que todos os alunos devem adquirir ao longo da Educação Básica, a começar pela primeira etapa, a Educação Infantil. Baseia-se nos documentos anteriormente publicados, citando principalmente a Constituição de 1988 , a LDB e o PNE para mostrar sua consonância com os marcos legais, ou seja, com a própria história da construção da educação brasileira. Nesse sentido, deixa claro que se propõe a elucidar o "básico-comum" e não "o que é diverso em matéria curricular". Trata das "competências e diretrizes (que) são comuns" e não dos "currículos (que) são diversos". Com isso vai ao encontro da "concepção do conhecimento curricular contextualizado na realidade local, social e individual da escola e do seu alunado" (BRASIL, 2017, p.11).

Com isso, afirma estar consoante a meta sete do PNE (BRASIL, 2014a), reiterando

a importância de uma base nacional comum curricular para o Brasil, com o foco na aprendizagem como estratégia para fomentar a qualidade da educação básica em todas as etapas e modalidades (BRASIL, 2017, p.12).

Reconhece as desigualdades educacionais naturalizadas ao longo da história brasileira e faz uma ampla explanação sobre o direito de todos à educação e aos princípios de igualdade e equidade, estabelecendo que a BNCC "explicita as aprendizagens essenciais que todos os estudantes devem desenvolver e expressa, portanto, a igualdade educacional sobre a qual as singularidades devem ser consideradas e atendidas" (p.15). Quanto à equidade, seria efetivada nos âmbitos das secretarias, a partir de suas decisões curriculares e didático pedagógicas. Destaca a necessidade de um trabalho de colaboração entre as diferentes instâncias e esferas da federação, responsáveis pela educação. Segundo o documento, equidade "pressupõe reconhecer que as necessidades dos estudantes são 
diferentes" (p.15).

O texto fala muito sobre a elaboração do currículo considerando as realidades particulares e essa ênfase valoriza a autonomia e competência das redes de ensino. Segundo a BNCC,

com a homologação da BNCC, as redes de ensino e escolas particulares terão diante de si a tarefa de construir currículos, com base nas aprendizagens essenciais estabelecidas na BNCC, passando, assim, do plano normativo propositivo para o plano da ação e da gestão curricular que envolve todo o conjunto de decisões e ações definidoras do currículo e de sua dinâmica (BRASIL, 2017, p.20).

Fica claro no documento sua orientação pelas DCNEB e que o currículo da instituição deve ser norteado pelos princípios éticos, estéticos e políticos, tendo como propósitos a formação humana integral e a construção de uma sociedade justa, democrática e inclusiva (BRASIL, 2017).

Nessa perspectiva, a BNCC pretende apresentar aos profissionais da educação um ponto de partida para a organização curricular que atenda o trabalho nas instituições de educação infantil. Entretanto, no âmbito do atendimento ao berçário, questões discutidas no meio acadêmico devem ser consideradas. Como seria uma proposta pedagógica no contexto da educação de crianças de zero a 18 meses? Na perspectiva da rotina do atendimento a esta faixa etária, que tem características específicas, como se colocam os objetivos definidos na BNCC? E, por fim, como será a formação dos professores para lidar com tais especificidades?

Ao analisarmos a estrutura da BNCC nos deparamos com alguns aspectos que comentamos a seguir para tentar responder a estas questões.

Inicialmente $\mathrm{o}$ documento mostra os fundamentos pedagógicos no qual se baseia e define competência como

a mobilização de conhecimentos (conceitos e procedimentos), habilidades (práticas, cognitivas e socioemocionais), atitudes e valores para resolver demandas complexas da vida cotidiana, do pleno exercício da cidadania e do mundo do trabalho (BRASIL, 2017, p.08).

Com isso, acredita assegurar o direito de aprendizagem a todos os alunos, endossando seu compromisso com a educação integral, considerando o contexto e os desafios da sociedade. Enumera 10 competências gerais para a Educação Básica que explicitam "o compromisso da educação brasileira com a formação humana integral e com a construção de uma sociedade justa, democrática e inclusiva" (BRASIL, 2017, p. 07).

Na divisão da Educação Básica em Infantil e Fundamental propõe formas diferentes na proposição das Competências gerais da Base Nacional Comum Curricular. Na Educação infantil, encontramos os Direitos de aprendizagem e desenvolvimento e os Campos de Experiências que se subdividem, nas faixas etárias - bebês $(0$ - 1a6m), crianças bem pequenas $(1 \mathrm{a} 7 \mathrm{~m}-3 \mathrm{a} 11 \mathrm{~m})$ e crianças pequenas $(4 \mathrm{a}-5 \mathrm{a} 11 \mathrm{~m})-\mathrm{e}$ nos objetivos de aprendizagem e desenvolvimento. No ensino fundamental os termos mudam - campos de experiências são substituídos por áreas de conhecimento, que são destrinchadas em Competências específicas da área, Componentes curriculares e Competências específicas por componente. Por fim, esses se subdividem pelos Anos Iniciais e Finais (sem faixa etária), contemplando Unidades temáticas, objetos de conhecimento e habilidades.

Parece interessante e até óbvio que as áreas não apareçam explicitamente na Educação Infantil. Falamos explicitamente porque estão implícitas e poderão ser entendida diferentemente pelas instituições que irão organizar seus projetos pedagógicos. É importante que se entenda a essência dessa diferença, diretamente relacionada às características da faixa etária, conforme se organiza a educação básica no Brasil. No entanto, a ideia de habilidades e objetos de aprendizagem adotadas como nomenclatura para o Ensino Fundamental parecem configurar e ser mais claros que objetivos de aprendizagem e desenvolvimento. Não há explicação relacionada à tal diferenciação e o que se observa são os conceitos dados pelo documento.

Em relação às habilidades, "expressam as aprendizagens essenciais que devem ser asseguradas aos alunos nos diferentes contextos escolares" (BRASIL, 2017, p.29) e são descritas com uma estrutura que inclui um verbo (processos cognitivos envolvidos na habilidade), componente do verbo (objeto de conhecimento) e modificadores do verbo ou de seu complemento (explicitam o contexto e/ou uma maior especificação da aprendizagem esperada). Essa forma de descrever as habilidades, com certeza, propicia segurança em relação aos objetos de conhecimentos que devem ser dominados pelo educando.

Já os objetivos de aprendizagem $e$ desenvolvimento da educação infantil são definidos como aprendizagens essenciais que 
compreendem tanto comportamentos, habilidades e conhecimentos quanto vivências que promovem aprendizagem e desenvolvimento nos diversos campos de experiências, sempre tomando as interações e brincadeiras como eixos estruturantes (BRASIL, 2017, p.42).

Primeiramente, não há qualquer menção sobre a definição de aprendizagem $e$ desenvolvimento para melhor entendimento dessa expressão. Em várias partes do documento essa expressão aparece com os termos aprender/desenvolver atrelados. Essa expressão já está presente nas DCNEI e nas DCNEB.

$\mathrm{Na}$ versão preliminar do documento Por uma política curricular para a educação básica: contribuição ao debate da base nacional comum a partir do direito à aprendizagem e ao desenvolvimento há entendimento dessa expressão dentro do contexto de um projeto pedagógico que responda às condições e possibilidades dos diferentes sujeitos de exercerem o direito de aprender e desenvolver-se: "Aprendizagem e desenvolvimento impostos na perspectiva do direito deverão se constituir em balizadores das propostas curriculares"(BRASIL, 2014b, p. 38). Assim, segundo este documento há necessidade de compreensão dos dois processos: aprendizagem e desenvolvimento.

Essa versão preliminar enfatiza que a processos de aprendizagem, distintos entre os sujeitos e que acontecem em diferentes esferas e circunstâncias, têm significações e sentidos que promovem novas aprendizagens e interferem no desenvolvimento, formando um "continuum, no qual saberes e conhecimentos não se constituem em coisa estranha, apartada da história dos sujeitos e dos grupos que lhes conferem identidade" (BRASIL, 2014b, p.38). Destaca que

à escola cabe, pois, o papel de oferecer o efetivo acesso a conhecimentos e experiências necessárias para que a criança, o adolescente ou $o$ adulto possam aprender e desenvolver-se. Para que isto se realize deverão ser respeitadas suas condições de cognição, de motivação e de familiaridade com formas e processos de representação das diferentes dimensões da realidade (BRASIL, 2014b, p.38).

Nesse sentido, o documento faz várias menções sobre as particularidades do desenvolvimento de cada indivíduo, assim como das generalidades, advindas de aspectos sociais, políticos e econômicos, mas que promovem experiências que, em conjunto, se tornam significativas ao sujeito. Isso se reflete no currículo, que

construído na perspectiva do Direito ao Desenvolvimento e à Aprendizagem, reorienta o foco do processo educativo. Os conhecimentos científicos e tecnológicos, as artes e as respectivas linguagens que expressam estes domínios se justificam como componentes curriculares quando se constituem caminhos para se chegar a compreensão da complexa dinâmica - próxima ou remota - em que o sujeito está imerso. A contextualização imporá diferentes níveis de domínio de informação e da articulação entre eles (BRASIL, 2014b, p.43).

Na nossa opinião valeria, ainda que breve, uma explanação sobre o entendimento que o documento tem sobre aprendizagem e desenvolvimento, uma vez que mostra respeito à diversidade de possibilidades de experiências advindas de outras esferas e assume

que a formação integral se constitui numa proposta de educação escolar que possibilita o acesso e a apropriação de conhecimentos e saberes presentes nas várias instâncias culturais da sociedade e compreende o ser humano a partir de uma visão que articula cognição, emoção, subjetividade, desejos, inteligibilidade, sociabilidade, entre outros aspectos, estimulando a gradativa autonomia dos estudantes em sua formação humana (BRASIL, 2014b, p.44).

Por fim, o documento descreve o que considera ser os seis direitos de aprendizagem e desenvolvimento na Educação Infantil: conviver com os diferentes sujeitos na sociedade, brincar diversamente, participar (ativamente) do cotidiano escolar nos diferentes âmbitos, explorar atividades e objetos (das artes, escrita, ciência e tecnologia), expressar por diferentes linguagens e conhecer-se formando identidade pessoal, social e cultural. Todos esses direitos devem ser afirmados para a criança por uma prática pedagógica com intencionalidade educativa e utilizando as interações e brincadeiras como eixos estruturantes, compartilhando do que já tem sido declarado em outros documentos.

$\mathrm{Na}$ DCNEI esses eixos (norteadores) aparecem para garantir experiências relacionadas às práticas pedagógicas que compõem a proposta curricular da Educação Infantil. A brincadeira já 
teve destaque em documentos anteriores, como no RCNEI (BRASIL, 1998a) e nos Parâmetros de Qualidade para a Educação Infantil (BRASIL, 2006). Esse entendimento é importante, pois como destaca Vitta et al. (2017, p.104)

o brincar proporciona oportunidades e experiências que exigem da criança a aquisição, treino e aprimoramento das habilidades motoras, cognitivas e emocionais para ter autonomia e independência e, com isso, agir sobre o meio, apreendê-lo e modificá-lo deixando sua marca enquanto ser social.

Considerar as interações e brincadeiras como eixos norteadores é caminhar para um entendimento dos direitos da criança respeitando-a. Devemos, no entanto, considerar que oferecer possibilidades do brincar (e não brinquedos aleatoriamente) para crianças tão pequenas é uma tarefa difícil, fato já apontado em alguns estudos (VITTA et al., 2015; MOREIRA et al., 2014). Ainda, é preciso que se assuma que há uma série de atividades no cotidiano da instituição educacional que atende a criança de zero a $1 \mathrm{a} 6 \mathrm{~m}$, consideradas como cuidado e que não envolvem claramente o brinquedo (embora pudessem). Nessas atividades, a interação é peça básica, mas tem que ser entendida como parte da educação.

A dicotomia cuidado $\mathrm{x}$ educação que envolve a identidade da creche, particularmente no atendimento às crianças menores, acaba por nortear as atividades desenvolvidas, o tempo e o espaço, comprometendo os objetivos educacionais. É preciso que esse tema seja incorporado e discutido durante a organização da proposta pedagógica.

Na BNCC (BRASIL, 2017, p.38), a questão da interação é focada quando se discute os campos de experiências, em especial $O \mathrm{eu}$ o outro e o nós, sendo que nesse campo a menção sobre as atividades de cuidados define que "ao mesmo tempo que participam de relações sociais e de cuidados pessoais, as crianças constroem sua autonomia e senso de autocuidado, de reciprocidade e de interdependência com o meio". Volta a falar explicitamente no campo de experiências Corpo, gestos e movimentos

na Educação Infantil, o corpo das crianças ganha centralidade, pois ele é o partícipe privilegiado das práticas pedagógicas de cuidado físico, orientadas para a emancipação e a liberdade e não para a submissão. Assim a instituição escolar precisa promover oportunidades ricas para que as crianças possam, sempre animadas pelo espírito lúdico e na interação com seus pares, explorar e vivenciar um amplo repertório de movimentos, gestos, olhares, sons e mímicas com o corpo, para descobrir variados modos de ocupação e uso do espaço com o corpo (tais como sentar com apoio, rastejar, engatinhar, escorregar, caminhar apoiando-se em berços, mesas e cordas, saltar, escalar, equilibrar-se, correr, dar cambalhotas, alongar-se etc.) (BRASIL, 2017, p. 39).

$\mathrm{Na}$ leitura dessas concepções, uma pessoa que entenda como se dá o desenvolvimento da criança pequena, a relação entre suas atividades e o desenvolvimento sensorial, motor, cognitivo, afetivo, poderá vislumbrar a prática pedagógica que considera as atividades de cuidado apropriadas para ensinar e para a criança aprender. No entanto, esse entendimento extremamente importante para a criança até $1 \mathrm{a} 6 \mathrm{~m}$ é raro no meio pedagógico.

Em nossos estudos sobre a oferta de educação para esta criança, esse problema sempre está presente, talvez por uma falta de convicção de que essa criança tenha direito a educação. Nos parece que ainda há um resquício de dúvida sobre isso e que o Brasil só ofereceu e incorporou o atendimento às crianças pequenas por uma necessidade social, da mãe trabalhadora. Enquanto não assumirmos a educação como um direito da criança, seja de que idade for, ela não será legítima e comprometida com seu desenvolvimento integral.

Os demais campos de experiências também se remetem às interações e brincadeiras, mas não de forma clara. Uma possibilidade para melhor entendimento se dá na análise dos objetivos traçados para cada campo de experiência para a faixa etária de 0 a $1 \mathrm{a} 6 \mathrm{~m}$.

Analisando o conteúdo da BNCC, é perceptível que há certa similaridade com o que está posto no RCNEI, pois embora as nomenclaturas sejam diferentes em cada documento, na análise de seus objetivos observa-se aproximações. No RCNEI encontram-se os Eixos Temáticos enquanto que na BNCC verificam-se os Campos de Experiências. Por exemplo, no RCNEI há o Eixo Temático Movimento, enquanto na nova proposta de base curricular há o Campo de Experiências Corpo, Gestos e Movimentos. O QUADRO 1 mostra algumas dessas similaridades, equiparando os eixos temáticos e os campos de experiências, assim como os objetivos propostos. 
QUADRO 1 - Quadro comparativo dos objetivos listados no RCNEI e BNCC

\begin{tabular}{|c|c|c|c|}
\hline \multicolumn{2}{|r|}{ RCNEI } & \multicolumn{2}{|r|}{ BNCC } \\
\hline Eixos temáticos & Objetivos para crianças de 0 a 3 anos & $\begin{array}{l}\text { Campo de } \\
\text { Experiência }\end{array}$ & Objetivos para crianças de 0 a 1a6m \\
\hline \multirow{2}{*}{ Movimento } & $\begin{array}{l}\text { Explorar as possibilidades de gestos e } \\
\text { ritmos corporais para expressar-se nas } \\
\text { brincadeiras e nas demais situações de } \\
\text { interação. }\end{array}$ & \multirow{2}{*}{$\begin{array}{l}\text { Corpo, gestos e } \\
\text { movimentos }\end{array}$} & $\begin{array}{l}\text { Experimentaras possibilidades } \\
\text { corporais nas brincadeiras e interações } \\
\text { em ambientes acolhedores e } \\
\text { desafiantes. }\end{array}$ \\
\hline & $\begin{array}{l}\text { Explorar e utilizar os movimentos de } \\
\text { preensão, encaixe, lançamento etc., } \\
\text { para o uso de objetos diversos. }\end{array}$ & & $\begin{array}{l}\text { Utilizar os movimentos de preensão, } \\
\text { encaixe e lançamento, ampliando suas } \\
\text { possibilidades de manuseio de } \\
\text { diferentes materiais e objetos. }\end{array}$ \\
\hline Música & $\begin{array}{l}\text { Brincar com a música, imitar, inventar } \\
\text { e reproduzir criações musicais. }\end{array}$ & \multirow{2}{*}{$\begin{array}{l}\text { Traços, sons, } \\
\text { cores e formas }\end{array}$} & $\begin{array}{l}\text { Explorar diferentes fontes sonoras e } \\
\text { materiais para acompanhar } \\
\text { brincadeiras cantadas, canções, } \\
\text { músicas e melodias. }\end{array}$ \\
\hline Artes visuais & $\begin{array}{l}\text { Utilizar diversos materiais gráficos e } \\
\text { plásticos sobre diferentes superfícies } \\
\text { para ampliar suas possibilidades de } \\
\text { expressão e comunicação. }\end{array}$ & & $\begin{array}{l}\text { Traçar marcas gráficas, em diferentes } \\
\text { suportes, usando instrumentos riscantes } \\
\text { e tintas. }\end{array}$ \\
\hline $\begin{array}{l}\text { Linguagem oral } \\
\text { e escrita }\end{array}$ & Interessar-se pela leitura de histórias; & $\begin{array}{l}\text { Escuta, fala, } \\
\text { pensamento e } \\
\text { imaginação }\end{array}$ & $\begin{array}{l}\text { Demonstrar interesse ao ouvir histórias } \\
\text { lidas ou contadas, observando as } \\
\text { ilustrações e os movimentos de leitura } \\
\text { do adulto-leitor (modo de segurar o } \\
\text { portador e de virar as páginas). }\end{array}$ \\
\hline
\end{tabular}

Fonte: elaborada pelos autores, baseados nos documentos RCNEI (1998b) e BNCC (2017)

No Eixo temático Matemática dos RCNEI, não foi possível encontrar semelhança com o Campo de Experiência Espaços, tempos, quantidades, relações e transformações da $\mathrm{BNCC}$, pois está realmente supera completamente o primeiro, colocando objetivos relacionados a conceitos que são primordiais para o entendimento do que se pode chamar de "ciências exatas" e que envolvem, como em outros campos de experiência, a psicomotricidade e a experimentação do espaço de forma a desenvolver o pensamento lógico e o entendimento da relação entre os sujeitos, os objetos e as transformações advindas dessas situações.

Enquanto se tem na matemática do RCNEI o objetivo para 0 a 3 anos: "estabelecer aproximações a algumas noções matemáticas presente no seu cotidiano, como contagem, relações espaciais etc." (BRASIL, 1998b, p.215) no eixo correspondente da BNCC observa-se objetivos mais palpáveis, como: "explorar e descobrir as propriedades dos objetos e materiais (odor, cor, sabor, temperatura)"; "explorar relações de causa e efeito (transbordar, tingir, misturar, mover e remover etc.) na interação com o mundo físico"; "manipular materiais diversos e variados para comparar as diferenças e semelhanças entre eles", dentre outros (BRASIL, 2017, p.49).

Podemos dizer, de modo geral, que na BNCC alguns desse objetivos são mais claros e auxiliam inclusive o professor na organização das atividades que serão propostas junto às crianças.

Considerando que os objetivos devem possibilitar a verificação da eficiência do processo de ensino e aprendizagem, os verbos usados são relevantes. Verbos que descrevem ações são palpáveis, como identificar, selecionar, manipular e possibilitam melhor entendimento pelos profissionais que devem pensar nas atividades desenvolvidas no contexto escolar para atingir seus objetivos. Verificamos que alguns objetivos são claros ao referirem-se às crianças ou seja, ao que elas deverão conseguir fazer, como experimentar, movimentar, imitar.

Outros verbos, usados nesse documento permitem entendimento mais diversificado, ou seja, são difíceis de concretizar e, obviamente, de avaliar se os objetivos foram ou não atingidos. Como exemplo, podemos citar "perceber que suas ações têm efeitos nas outras crianças e nos adultos" (BRASIL, 2017, p. 43), ao qual podemos perguntar: o que isso significa na prática? Fica difícil para o professor delimitar o alcance dos mesmos já que 
trata de uma ação abstrata, de difícil mensuração. Dessa forma, o planejamento e a avaliação do desenvolvimento e da aprendizagem das crianças se tornam mais subjetivas aos professores, já que eles terão que, a partir desses objetivos (que são amplos) e de acordo com seu entendimento, criar outros mais específicos de acordo com a turma com que estiver trabalhando e com o projeto pedagógico da instituição.

Destacamos, no entanto, que esse problema era maior na versão preliminar, sendo que na final, muitos destes objetivos foram reescritos e melhorados, no sentido de favorecer o seu entendimento. Essa elaboração com mais objetividade, pensando no desenvolvimento de habilidades e capacidades, possibilitarão à criança aprendizagens mais significativas ligadas à instituição educacional, podendo colaborar efetivamente para a construção de uma proposta pedagógica para a educação da criança de zero a 1a6m. Esse documento, construído coletivamente é importante para diminuir o espontaneísmo visto nas práticas junto à criança pequena, por uma "tradução" dos objetivos em ações feita pelos professores e permitida pelos documentos oficiais.

A BNCC traz um foco maior que documentos anteriores à educação dos bebês, apresentando objetivos de aprendizagem que vão além dos cuidados, porém ainda pouco instrumentais no que tange a metodologias aplicáveis para se atingir a indissociabilidade de cuidado e educação, ficando esse papel a cargo das instituições e profissionais.

Casanova (2016, p. 42) afirma que "as crianças permanecem, em média, cerca de dez horas nas instituições de Educação Infantil e vivenciam situações diversas, em espaços específicos e com uma rotina estabelecida. Nesse ambiente, elas comem, brincam, socializam-se, são cuidadas e educadas." A partir deste olhar, pressupõe-se que há uma currículo que orienta as práticas dessas pessoas na relação com as crianças. Podemos afirmar que, no atual contexto da educação infantil, o RCNEI e as DCNEIs têm um importante papel na execução dessas práticas, bem como as experiências de vida que constituem a formação desses profissionais.

Nesse sentido, entendemos que a BNCC deverá ser a maior referência na qual os profissionais da educação irão se pautar para planejar suas ações junto às crianças, pois como seu próprio título indica trata-se de uma base, ou seja, um suporte, no qual se firmarão os conhecimentos e experiências proporcionados as crianças.
Há necessidade de especial atenção à fase da educação infantil para que as práticas consigam mudar seu foco do assistencialismo e passem para um entendimento de direito das crianças a oportunidades que promovam seu desenvolvimento integral.

No entanto, o texto acima nos leva a pensar, por fim, numa questão extremamente importante: estão os profissionais que atuam na educação infantil, junto à criança de zero a $1 \mathrm{a} 6 \mathrm{~m}$, capacitados para atender à $\mathrm{BCNN}$ ?

Becker, Bernardi e Martins (2013) verificaram em sua pesquisa a dissociação entre práticas de cuidado e de estimulação no discurso de educadoras de berçário e consideram a importância de uma formação específica para o trabalho com crianças nessa faixa etária, possibilitando que as profissionais tenham maior entendimento sobre aspectos desenvolvimentais do bebê.

Segundo a BNCC (BRASIL, 2017, p.21),

a primeira tarefa de responsabilidade direta da União será a revisão da formação inicial e continuada dos professores para alinhá-las à BNCC. A ação nacional será crucial nessa iniciativa, já que se trata da esfera que responde pela regulamentação do ensino superior, nível no qual se prepara grande parte desses profissionais. Diante das evidências sobre o peso do professor na determinação do desempenho do aluno e da escola de educação básica, essa é uma condição indispensável para a implementação da BNCC.

O próprio documento fala sobre a necessidade de se repensar na formação do professor, sendo essencial que esse repensar inclua especificidades relacionadas à aprendizagem e desenvolvimento das faixas etárias atendidas pela Educação Infantil.

É preciso um profissional que saiba sobre desenvolvimento da criança e como acontece a aprendizagem entre zero a $1 \mathrm{a} 6 \mathrm{~m}$, como se organizam as atividades utilizando os eixos norteadores interações e brincadeiras para atingir os objetivos estipulados.

Na questão das brincadeiras, por exemplo, é preciso que o professor conheça os diferentes brinquedos disponíveis para essa faixa etária, saiba como brincar com eles e o que promovem para a criança, ou seja, que habilidades exigem que ela tenha e quais estimulam a aquisição. Tudo isso, baseado nos objetivos educacionais para a essa fase da educação (VECTORE, 2003; LIMA; BHERING, 
2006; BALTIERI et al., 2010; VITTA et al., 2017).

Como diz Vitta et al. (2017, p. 106)

é preciso que a proposição de atividades do brincar (assim como as de alimentação, vestuário e higiene) seja intencional, ou seja, devem ser pensadas, planejadas e adaptadas para atender a objetivos direcionados às crianças, às habilidades e conhecimentos que se quer que ela desenvolva ou aprenda.

Essa premissa encontra-se na BCNN (BRASIL, 2017, p.36) quando se destaca a "necessidade de imprimir intencionalidade educativa às práticas pedagógicas na Educação Infantil, tanto na creche quanto na pré-escola".

É preciso que o profissional da creche seja valorizado e essa valorização se inicia na formação, dando lugar a conteúdos que auxiliem no entendimento dessa fase do desenvolvimento infantil e dos contextos que envolvem a aprendizagem. Ou seja, a creche e a educação da criança pequena requerem um profissional que conheça as especificidades da docência nessa fase para atuar em um projeto em que sua ação seja pedagógica. Como ressaltam Campos et al. (2011a, 2011b) em seus trabalhos, uma creche de boa qualidade impacta de forma positiva no futuro da criança, principalmente pelo oferecimento de experiências que promovam seu desenvolvimento integral, considerando que estas são organizadas e planejadas por profissionais que atuam junto a essa fase da educação.

Se a formação não for uma das prioridades na reorganização da educação básica brasileira, de nada valerão os documentos, com seus indicativos do mínimo de qualidade para toda a população, respeitando todas as diferenças existentes nesse país, pois não haverá quem os coloque em prática, quem organize os espaços e tempos, quem selecione e oriente a compra de materiais apropriados, quem interaja e promova a atividade da criança na faixa etária até $1 \mathrm{a} 6 \mathrm{~m}$.

Nesse sentido, estudar com afinco esta fase é tarefa de todos que estudam e se preocupam com a aprendizagem e desenvolvimento integral da criança, possibilitando que a proposta pedagógica e as atividades organizadas na rotina da instituição educacional caminhem para além do cuidado e se distanciem do assistencialismo que por muito tempo permaneceu (e permanece ainda) na educação das crianças pequenas.

\section{Referências}

AMORIM, A. L. N.; DIAS, A. A. Currículo e educação infantil: uma análise dos documentos curriculares nacionais. Espaço do Currículo, v. 4, n. 2, p. 125-137, 2012.

BALTIERI, L. et al. Desempenho motor de lactentes frequentadores de berçários em creches públicas. Rev. Paul. Pediatria, v. 28, n. 3, p. 283289, 2010.

BECKER, S. M. S.; BERNARDI, D.; MARTINS, G. D. F. Práticas e crenças de educadoras de berçário sobre cuidado. Psicologia em Estudo, Maringá, v. 18, n. 3, p. 551-560, jul./set. 2013.

BRASIL. Ministério de Educação e Cultura. LDB Lei $\mathrm{n}^{\circ}$ 9394/96, de 20 de dezembro de 1996. Estabelece as diretrizes e bases da Educação Nacional. Brasília: MEC, 1996 .

. Proposta pedagógica e currículo em educação infantil: um diagnóstico e a construção de uma metodologia de análise/Ministério da Educação e do Desporto. Secretaria de Educação Fundamental. Departamento da Política de Educação Fundamental. Coordenação-Geral de Educação Infantil. Brasília: MEC/SEF/ DPEF/COEDI, 1996b.

Ministério da Educação e do Desporto. Secretaria da Educação Fundamental. Referencial Curricular Nacional para Educação Infantil. v. 1. Brasília, DF: MEC/SEF/Coedi, 1998a.

. Ministério da Educação e do Desporto. Secretaria da Educação Fundamental. Referencial Curricular Nacional para Educação Infantil. v. 3. Brasília, DF: MEC/SEF/Coedi, 1998 b.

Ministério da Educação. Secretaria de Educação Básica. Parâmetros Nacionais de qualidade para a educação infantil. Brasília: MEC, SEB, 2006.

- Ministério da Educação. Secretaria de Educação Básica. Diretrizes curriculares nacionais para a educação infantil / Secretaria de Educação Básica. Brasília: MEC, SEB, 2010.

Ministério da Educação. Secretaria de 
Educação Básica. Diretrizes Curriculares Nacionais Gerais da Educação Básica/Ministério da Educação. Secretaria de Educação Básica. Diretoria de Currículos e Educação Integral. - Brasília: MEC, SEB, DICEI, 2013.

Ministério da Educação. Lei $n^{\circ} 13.005$ Plano Nacional de Educação - PNE. Brasília: INEP, 2014a. Disponível em:

$<$ http://fne.mec.gov.br/images/doc/pne-201420241.pdf>. Acesso em 03 set. 2014.

. Por uma política curricular para a educação básica: contribuição ao debate da base nacional comum a partir do direito à aprendizagem e ao desenvolvimento. Versão Preliminar. Brasília, MEC. Secretaria da Educação Básica. Diretoria de Currículos e Educação Integral, 2014b. Disponível em: www.gper.com.br/biblioteca_download.php?arquiv oId=1003. Acessoem: 20/11/2016.

Ministério da Educação. Base Nacional Comum Curricular. Secretaria de Educação Básica. Brasília: MEC, SEB, 2017.

CAMPOS, M.M. et al.A qualidade da educação infantil: um estudo em seis capitais brasileiras. Cadernos de Pesquisa, v, 41, n. 142, p. 20-54, $2011 \mathrm{a}$.

CAMPOS, M. M. et al. A contribuição da educação infantil de qualidade e seus impactos no início do ensino fundamental. Educação e Pesquisa, São Paulo, v.37, n.1, p.15-33, 2011 b.

CASANOVA, L. V. Creche e família ou creche e famílias: o contexto dessa relação na contemporaneidade. Horizontes, v. 34, n. 2, p. 4148, ago./dez. 2016.

COUTINHO, A. S. As políticas para a educação de crianças de 0 a 3 anos no Brasil: avanços e (possíveis) retrocessos. Laplage em Revista
(Sorocaba), vol. 3, n. 1, p. 19-28, jan.-abr. 2017.

LIMA, A. B. R. ; BHERING, E. Um estudo sobre creches como ambiente de desenvolvimento. Cadernos de Pesquisa, v. 36, n. 129, p. 573-596, set./dez.2006.

MOREIRA, D. S. et al. Influência de procedimentos educativos. Revista Terapia Ocupacional USP, v. 25, p. 217-224, set./dez. 2014.

ROSEMBERG, F. A criança pequena e o direito à creche no contexto dos debates sobre infancia e relações raciais. In: BENTO, M. A. B. (Org.) Educação infantil, igualdade racial e diversidade:aspectos políticos, jurídicos, conceituais. São Paulo: Centro de Estudos das Relações de Trabalho e Desigualdades - CEERT, 2012. p.10-46.

VECTORE, C. O brincar e a intervenção mediciacional na formação continuada de professores de educação infantil. Psicologia USP, v. 14, n. 3, p. 105-131, 2003.

VITTA, F.C.F.; SILVA, C.C.B.; ZANIOLO, L.O. Educação da criança de zero a três anos e educação especial: uma leitura crítica dos documentos que norteiam a Educação Básica. Rev. Bras. Ed. Esp., Marília, v. 22, n. 1, p. 9-26, Jan.-Mar., 2016.

VITTA, F. C. F. et al. The Play in the Context os Early Childhood Education in the View of Nurseries Professionals. Creative Education, 6, p. 519-525, 2015.

VITTA et al. O brincar de 0 a 2 anos no contexto da educação infantil. In: OLIVEIRA, J. P.; ROCHA, A. N. D.; MIURA, R. K. K.; RODRIGUES, E. S. (Org.)Desenvolvimento infantil, escola e inclusão: ações pedagógicas e intersetoriais. Curitiba, PR: CRV, 2017, p. 95-118.

\section{Sobre as autoras}

Fabiana C. F. Vitta é professora do Programa Pós-Graduação em Educação Escolar da Unesp/Araraquara, na linha de pesquisa Formação do professor, trabalho docente e práticas pedagógicas e no Departamento de Educação Especial da Unesp/Marília. Mestre e Doutora em Educação Especial (UFSCar), é coordenadora do Grupo de Estudos e Pesquisa em Atividades e Desenvolvimento Infantil - GEPADI, com pesquisas na área de Educação Infantil. 
Girlene de Albuquerque Cruz é mestranda no Programa de Pós-graduação em Educação Escolar na UNESP Araraquara. Graduada em Pedagogia pela Universidade Federal do Pará e Pós-graduada Lato Sensu em Administração Escolar, Orientação e Supervisão - Centro Universitário Leonardo Da Vinci. Professora formadora dos professores da Educação Infantil da Rede Municipal de Ensino de Marabá - PA.

Bárbara S. Scarlassara é mestranda no Programa de Pós-graduação em Educação Escolar na UNESP Araraquara. Graduada em Terapia Ocupacional pela Universidade Estadual Paulista Júlio de Mesquita Filho. Cursou Aperfeiçoamento em Intervenção Precoce no Núcleo de Estudos em Neuropediatria e Motricidade da Ufscar. Atuou no Centro de Reabilitação SORRI na cidade de Bauru - SP e na Prefeitura Municipal de Pederneiras.

Recebido em novembro de 2017.

Aprovado em março de 2018. 